\title{
AS PERSONAGENS-TIPO DA SÍNDROME DO PROTAGONISTA MIDIÁTICO
}

\author{
THE CHARACTER TYPES OF THE MEDIA PROTAGONIST \\ LOS PERSONAJES-TIPO DEL PROTAGONISMO MEDIÁTICO
}

\author{
Ana Luiza Coiro-Moraes \\ Doutora, Universidade Federal de Santa Maria \\ anacoiro@gmail.com
}

\section{Resumo}

Herdeiras da estética do folhetim -- a exacerbação emocional das propostas do Romantismo -e do fait divers -- a fórmula folhetinesca do jornalismo --, as personagens midiáticas compõem uma tipologia. E como modelos de atuação, essas personagens-tipo se fazem presentes nos programas que alçam sujeitos comuns à visibilidade midiática, os espetáculos de realidade. Tais programas são típicos de um tempo que se caracteriza como uma modernidade exacerbada, urdida nos suportes tecnológicos da comunicação, a deslocar noções e práticas do espaço privado para o virtual espaço público criado pela mídia. Apresenta-se, neste trabalho, uma proposta de mapeamento dessas personagens que transitam nesse espaço-tempo como oferta de lazer e entretenimento da televisão.

Palavras-Chave: Protagonismo midiático. Espetáculos de realidade. Personagens-tipo.

\begin{abstract}
Heirs of the feuilleton aesthetic - the emotional exacerbation of Romanticism's proposals and of fait divers - the feuilleton formula for journalism- today's media characters may be understood through a typology. As models of acting, these character types appear in programs that raise ordinary people to the heights of media visibility through reality spectacles. Such programs become common in a time which can be characterized as "exacerbated modernity", held up by the technological support of communications and shifting notions and practices that move from private space to the virtual public space created by the media. Our paper presents a proposal for mapping the characters that take their places in this time/space and discusses what they offer in terms of leisure and television entertainment.
\end{abstract}

Keywords: Media protagonist. Reality shows. Character types.

Esta obra está licenciada sob uma Licença Creative Commons 


\section{Resumen}

Herederos de la estética del feuilleton - exacerbación emocional de las ofertas del romanticismo - y del fait divers - la fórmula feuilletonistic del periodismo - los personajes mediáticos forman una tipología. Y como modelos a seguir, estos personajes-tipo están presentes en los programas que levantan el sujeto común a visibilidad en los medios, los espetáculos de realidade. Estos programas son típicos de una época que se caracteriza por un modernismo exacerbado, tejido en varios canales de comunicación tecnológica, cambiando las nociones y prácticas del espacio privado para el espacio público virtual creado por los medios de comunicación. Se presenta en este trabajo una propuesta para mapear estos personajes que se mueven en el espacio-tiempo como una oferta de ocio y entretenimiento de la televisión.

Palabras clave: Protagonismo mediático. Espetáculos de realidade. Personajes-tipo

\section{INTRODUÇÃO}

\subsection{A síndrome do protagonista midiático}

Este artigo se constrói à procura de um modo de aproximação aos sujeitos comuns que cada vez mais habitam o "mundo real” da mídia, mas que estranhamente parecem personagens transportadas da literatura e do teatro para as páginas de jornais e revistas ou para as telas da televisão e dos computadores ligados em rede. Eles se assemelham a seres ficcionais, mas são encenados na ‘realidade’ da programação midiática.

Esse estranhamento principia na observação do acréscimo de fontes “populares” nos textos e programas informativos, como se as tradicionais "fontes abalizadas", oficialmente instituídas por deter o conhecimento ou o poder, devam ser gradativamente substituídas por pessoas comuns, cujo contato com os acontecimentos noticiados se constitua de forma totalmente empírica.

Também no rádio percebe-se uma crescente programação cedendo espaço a sujeitos (e seus problemas) comuns, aparentemente em busca de benesses típicas da cidadania que por algum motivo não alcançaram por outras vias. A propagação de blogs e a diversidade de formas de expressão dos “comuns” propiciada pela rede mundial de computadores e pelo vasto mercado a ela agregado, estimulando práticas interativas, são alguns dos outros fatores de incremento da participação de "não-profissionais” na produção midiática.

Porém, não há dúvidas de que o estranhamento diante destas novas personagens do cenário midiático é aguçado sobremaneira a partir da maciça inserção das audiências nas grades de programação da televisão, nos shows “de realidade” cuja exibição vem proliferando indefinidamente. 
No imaginário fílmico houve alguma especulação sobre pessoas que se tornam personagens. Em A rosa púrpura do Cairo (Woody Allen, 1985), uma garçonete, ao tentar evadir-se da dura realidade de sua vida (desempregada e maltratada pelo marido), diariamente assistia ao mesmo filme, até o astro saltar da tela, apaixonado por ela. Em $O$ show de Truman, de 1998, um menino foi adotado por uma rede de televisão que transmitiu toda a sua vida para uma grande audiência. Apenas Truman era real e não sabia que sua cidade era cenográfica e sua esposa, pais e amigos eram atores.

Nessas obras, no entanto, ainda não há sujeitos conscientes de sua possibilidade de estrelar a própria vida em produções midiáticas. Já os sujeitos comuns que passam a atuar em espaços nobres da mídia (que até então apenas os acolhera como receptores), deliberadamente deixam suas condições triviais de vida para se tornarem personagens de espetáculos de realidade ${ }^{1}$. Personagens, porque se esses sujeitos se fazem presentes nos espaços midiáticos através de relatos originados na materialidade do vivido, a maneira como atuam remete ao imagético da ficção.

Então, do estranhamento em relação a temáticas da mídia que se constroem em torno de sujeitos comuns e de suas opiniões, experiências ou problemas absolutamente prosaicos e por isso mesmo tomados como proeminentes —, quando o envolvimento direto e pessoal parece ser o principal fator de noticiabilidade e o não-acontecimento a própria medida do que é atual e tem interesse público no sentido jornalístico, surge a perplexidade.

Perplexidade diante de sujeitos comuns que como personagens das próprias histórias são alçados à celebridade, ali se encontrando com modelos, atores, cantores, estilistas, jogadores de futebol, automobilistas (e suas respectivas namoradas ou ex-namoradas) e uma lista infindável que inclui jornalistas, intelectuais, escritores... Todos, indiscriminadamente, lançados à fama pelo princípio midiático da celebração de personalidades, por mais ordinárias que elas possam parecer sob outros valores estético-éticos.

Perplexidade porque parece haver uma reversão de expectativas nas práticas midiáticas. Enquanto as produções buscam aproximar-se de seus receptores travestindo-os em protagonistas do espetáculo (por vezes até explorando suas características pessoais como burlescas); as pessoas egressas do ambiente da recepção vestem o figurino daqueles que

\footnotetext{
${ }^{1}$ Emprega-se o termo espetáculo de realidade, a partir da tradução da expressão inglesa reality show, mas com sentido mais abrangente, isto é, não apenas fazendo referência aos programas de televisão cujos formatos são reconhecidos por esse título, mas estabelecendo uma relação com todo produto, veiculado em qualquer dos suportes midiáticos, que tenha como protagonistas da cena sujeitos comuns, cuja vivência ou problemas sejam lançados ao espetáculo.
} 
tradicionalmente ocupavam o espaço da produção: os famosos. E estes últimos passam a ser modelos de atuação para os candidatos ao protagonismo. Isto é, se é perceptível um movimento da mídia no sentido da inclusão dos “comuns” em sua programação, por outro lado, também é flagrante uma matriz de comportamento nesses sujeitos oferecendo-se à notoriedade. Trata-se da síndrome do protagonista.

Em busca de uma matriz de comportamento que identifique os sujeitos comuns no seu desejo de notoriedade, em primeiro lugar, toma-se a palavra síndrome, não na acepção médica, mas no seu sentido mais trivial (um conjunto de sinais indicativos de uma dada situação, compartilhada por determinado grupo de pessoas).

A outra palavra que se une a síndrome - protagonista - é oriunda do grego (proto, primeiro; agonistês, ator ou competidor), como informa Moisés (1974, p. 423), e se tornou necessidade vocabular quando as tragédias clássicas deixaram de ser recitadas apenas por um coro, transformando-se em diálogo entre o grupo uníssono e o primeiro ator, inovação que costumeiramente é creditada a Téspis, “o mais antigo trágico” (final do século VI a.C.), de acordo com Lesky (1976, p. 69-71). Já então se detectava a mescla do foco significativo da palavra protagonista entre o sujeito que atua e a personagem que é representada, mantendose tal ambigüidade através dos tempos, no teatro, na literatura, depois no rádio, no cinema e na televisão, onde quer que se apresente a ficção.

E eis que a síndrome do protagonista se apresenta como uma situação comum a sujeitos identificados pela necessidade de ocupar o primeiro plano no palco dos acontecimentos, alçados a uma condição para a qual ainda não detinham treinamento — atuar no cenário midiático —, mas contando com alguns referenciais já “testados” na própria observação dos eventos da mídia. Esta é a hipótese que aqui se apresenta para traçar uma tipologia dessas 'personagens'.

\section{O CENÁRIO}

A constatação da forma de atuação desses sujeitos “ordinários” nos ambientes midiáticos, da maneira como se articulam as cartas ou depoimentos nos meios impressos (ou nas telas internáuticas) à postura "teatralizada” que adotam nos programas de rádio e de televisão, isto é, àquilo que se poderia traduzir como um modo de "estar no espetáculo"; leva à reflexão sobre o próprio espetáculo, sobre a sua gramática e a sua onipresença que a tudo abarca — das notícias às audiências. 
Assim, um primeiro deslocamento na direção de uma conceituação de protagonismo dirige-se à abordagem teórico-metodológica que Canclini (2006) sugere chamar de "estudos sobre cultura”. Trata-se, segundo sua perspectiva, de uma alternativa latino-americana aos cultural studies britânicos, o campo que desde seus trabalhos fundadores ${ }^{2}$ vem engendrando novas práticas de análise, não sob o manto do rigor normativo ou dos preconceitos (das tradições acadêmicas ou de esquerda), mas desmistificando os padrões deste tipo de debate ao optar por observar as produções “preferidas do povo” como constitutivas da noção de cultura.

Por outro lado, alinhar-se a tal concepção analítica não significa abdicar de um posicionamento crítico em relação às motivações mercadológicas que especificam os paradigmas sob os quais se organiza o protagonismo midiático. Dessa forma, ao considerar a síndrome do protagonista uma condição cultural, intui-se que há um peculiar "espírito do tempo” a conceber suas personagens. Por isso, é preciso contextualizá-la em um particular projeto de modernidade, sob o prisma do espaço-tempo da contemporaneidade urdida na mídia; e atentando para o discurso auto-referencial e laudatório da sociedade do espetáculo, que é o próprio Zeigeist dessa pós, super ou mesmo hiper-modernidade, como quer Lipovetsky (2004), e que já havia sido vaticinado por Debord (1997 [1967]) bem antes que essas performances de comuns passassem a ser tão presentes.

Nessa modernidade, que é forjada na mídia, imperam as micro-narrativas dos comuns, sob o apoio da produção empresarial-mercantilista e do desenvolvimento técnico-científico, assumindo e estendendo a hábitos de vida regionais ou locais a sua lógica. E é nesse sentido que não se trata de um tempo “pós”, mas da exacerbação (e espetacularização) do que já havia no primeiro projeto de modernidade, apoiado pela expansão mercantilista e pelo progresso técnico propiciado pela Revolução Industrial.

À procura de uma forma de leitura para acessar essa nova maneira de estar no mundo, recorre-se a Raymond Williams, a fim de encontrar uma estrutura de sentimento que coloca em foco uma cultura onde o que se inscrevia como privado em outros tempos, hoje é o nãoacontecimento tornado público e estrelado pelo sujeito ordinário.

\footnotetext{
${ }^{2}$ Escosteguy (2001 p. 21-22) aponta três textos surgidos a partir do final dos anos 1950, na Grã-Bretanha, como a base fundadora dos estudos culturais: The Uses of Literacy (1957), de Richard Hoggart; Culture and Society (1958), de Raymond Williams; e The Making of the English Working-class (1963), de E. P. Thompson. Segundo essa autora: “O primeiro é em parte autobiográfico e em parte história cultural do meio do século XX. O segundo constrói um histórico do conceito de cultura, culminando com a ideia de que a 'cultura comum ou ordinária' pode ser vista como um modo de vida em condições de igualdade de existência com o mundo das Artes, Literatura e Música. E o terceiro reconstrói uma parte da história da sociedade inglesa de um ponto de vista particular — a história 'dos de baixo'”,
} 
Ao cunhar o conceito de estrutura de sentimento, Williams procurava por um termo que descrevesse e conciliasse idéias a priori antagônicas, como a materialidade das vivências do 'mundo real' - as estruturas - e a intangível seara dos sentimentos, ao mesmo tempo datando-as nas especificidades de cada momento histórico. Para Brennen (2003, p. 118), "metodologicamente, estrutura de sentimento fornece uma hipótese cultural que tenta entender os elementos materiais específicos, de uma específica geração, num tempo histórico também específico, dentro de um processo complexo de hegemonia”.

No entanto, se junto com os conceitos duros legatários de um estruturalismo de origem marxista é possível vislumbrar a concepção filosófica do Zeitgeist como elemento formador da idéia de estrutura de sentimento; também é perceptível que Williams (1979 [1977], p. 131132) de certa forma laiciza o aspecto demiúrgico contido neste conceito, conferindo o protagonismo histórico das mudanças sociais não à índole de uma época, mas à materialidade das experiências humanas. Todavia ele considera "o que é articulado" e "o efetivamente vivido” em um mesmo patamar hierárquico de concretude.

Para o que estamos definindo, trata-se de uma qualidade particular da experiência e do relacionamento sociais, historicamente distinta de outras qualidades particulares, que dá o sentido de uma geração ou de um período. As relações entre esta qualidade e outros específicos marcos históricos de mudança em instituições, formações e crenças, e, além disto, a mudança de relações sociais e econômicas entre e inter classes, é outra vez uma questão em aberto: quer dizer, um jogo de específicas questões históricas [...] Estamos falando sobre elementos característicos de impulso, restrição e tom; especificamente elementos afetivos da consciência e dos relacionamentos: não sentimento contra pensamento, mas pensamento como sentimento e sentimento como pensamento: consciência prática de um tipo de tempo presente, em vívida e inter-relacionada continuidade. Os grifos são nossos.

Assim, se o espaço-tempo cultural que favorece o surgimento da síndrome do protagonista possui uma estética própria, ela é constituída por dada estrutura de sentimento culturalmente construída no Ocidente. Historicamente, podem ser identificados os primeiros “sintomas” da formação de uma ágora para o protagonismo na movimentação de noções e práticas do espaço privado para o espaço público e na ritualística de espetáculo contida nesse deslocamento, que, aliás, já se dava entre os gregos e os romanos, quando feitos individuais alcançavam os espaços públicos e eram cultuados nos esportes, nos jogos e na arte.

Porém, é na estética romântica que se localiza o marco inaugural do protagonismo do sujeito ordinário: quando a burguesia assenta-se, historicamente enaltecida pelos direitos do 
homem (inclusive o direito inalienável à felicidade, como reza a Declaração da Independência norte-americana, de 1776), ao mesmo tempo se instaura um movimento artístico e cultural que eleva à nobreza as emoções e sentimentos de suas personagens e por isso distinguindo-as, independentemente de suas origens aristocráticas.

Contudo, para chegar às origens estéticas da síndrome do protagonista, a esses sinais da formação de condições culturais propícias aos espetáculos de realidade é preciso ainda acrescentar as formas dos folhetins - romances publicados nos rodapés dos jornais que marcam o surgimento da imprensa de grande tiragem, organizando-se como indústria cultural — e do fait divers, a realidade "com enredo".

O folhetim, entretenimento de alto envolvimento emocional, se mantém como expressão massiva e, adaptando-se aos novos suportes tecnológicos da indústria cultural do século XX, chega à cultura midiática como folhetim eletrônico: primeiramente, na forma de radionovela, para depois consagrar-se também na televisão. A telenovela, por vezes considerada como fio condutor para a implementação do capitalismo empresarial moderno no Brasil $^{3}$; no seu formato real-naturalista de representação e por suas temáticas sempre tão próximas da "verdade”, mas ao mesmo tempo diariamente "reencantando" a vida das pessoas comuns, aparece como um dos “modelos” utilizados pelo segmento da recepção quando se oferece à consagração em um espetáculo de realidade.

Dadas essas rápidas considerações sobre as estruturas de sentimento que levam aos tipos surgidos em algumas das formas ficcionais que lhes deram a base, eis o momento de buscar as "personagens” que emanam dos relatos midiáticos e suas interações com a cultura de onde emergem, considerando, todavia, a sua própria lógica de funcionamento: das intangíveis motivações psicológicas àquelas construídas através dos modelos de personagens extraídos da própria mídia.

\section{As personagens-tipo}

De certa forma, questiona-se a força de "humanidade" do tipo de personagens “reproduzidas" ou “inventadas” pelos sujeitos comuns quando se alçam a protagonistas das produções midiáticas, porque eles não são passíveis de enquadramentos na ideia de representação mimética da realidade, mas tampouco se tornam “reais” por estarem em um espetáculo de realidade, desempenhando o próprio papel: há também um “ser inventado” que não veicula conceitos no sentido filosófico, mas é a imagem de algo - movendo-se no

\footnotetext{
${ }^{3}$ Sobre este tema, ver ORTIZ, Renato. A moderna tradição brasileira. São Paulo: Brasiliense, 1994 [1988].
} 
universo onde se dá a possibilidade de interação afetiva entre "pessoas” e "personagens" midiáticas.

Por isso, equacionam-se as personagens midiáticas através de conceituações históricas que situaram "personagem” como categoria teórica do campo da literatura. Retrocedendo na linha de tempo do pensamento crítico ocidental, a interpretação da mimesis aristotélica aponta para a personagem como reflexo da pessoa, mas, também, como uma construção sob certas especificidades discursivas. Se a Poética afirma que o historiador e o poeta diferem, porque um diz o que aconteceu e o outro o que poderia ter sucedido, é possível pensar em aplicar essa conceituação às funções atualmente assumidas pela mídia: em primeiro lugar, porque é ela que hoje "diz as coisas que sucederam” e pauta os acontecimentos, no âmbito de seu discurso.

Estudos clássicos da teoria da literatura, na intenção de estabelecer a diferença entre as pessoas na vida cotidiana e as personagens na ficção, apresentaram propostas como a distinção entre personagens redondas e planas. As primeiras são aquelas cuja complexidade eleva-as a grandes figuras do plano existencial; já as planas, sem profundidade psicológica, construídas em torno de algumas características peculiares, são as personagens-tipo.

A classificação de Propp (1984), que identificou nos contos maravilhosos sete tipos básicos, a partir de suas “esferas de ação”, resulta até hoje em importante material para qualquer reflexão em torno de personagens de produções populares. Assim, o herói, a princesa, o antagonista, o falso herói, o mandante, o auxiliar e o doador formam a tipologia básica que categoriza as personagens planas.

Justamente nesta classificação de personagem plana é possível localizar uma conceituação para as personagens midiáticas, compostas a partir de suas precursoras: os seres ficcionais da commedia dell'arte e do romance-folhetim, mesclando-se e transmutando-se em personagens do fait divers, da radionovela, da telenovela, até a formação de modelos para atuação das personagens-tipo dos atuais espetáculos de realidade.

Nas improvisações da commedia dell'arte, o principal apoio eram as personagens, cujas máscaras, padronizando comportamento, linguagem e situações, identificavam o tipo que estava em cena. Essas personagens-tipo se apresentavam em duas categorias gerais: patrões e criados - subdivididas em jovens enamorados; velhos mercadores, doutores ou militares; e servos astutos ou broncos. Os contratempos pelos quais passavam os puros e ingênuos enamorados, confrontando-se com a ganância ou a lascívia dos velhos e ajudados pela esperteza e espírito prático dos criados, podem ser verificados, em sua essência, povoando a cena da dramaturgia folhetinesca dos dias de hoje. 
Já as personagens de folhetins estão presentes na origem da tipologia que se busca, em primeiro lugar, pela veiculação desse gênero de ficção através dos jornais, servindo-lhes inclusive como propulsor para seu estabelecimento como empresas, dada a função de atração mercantilista que exerciam entre os leitores. Outro aspecto é a presença das personagens planas nos folhetins, que se acredita estarem na gênese das personagens midiáticas: o herói e a heroína, sempre protagonistas das tramas; e o vilão e a vilã, seus antagonistas; cuja maniqueísta divisão entre personagens “do bem” ou "do mal” repetia-se nos coadjuvantes. Tipos reiterados em áudio, nas radionovelas, e eternizados também em imagens, no cinema hollywoodiano e nas telenovelas, até hoje.

Da mesma forma, embora na atualidade haja novos tipos na sua composição (como os articulistas dos jornais ou os apresentadores dos programas de rádios e televisão), a raiz de uma tipologia de personagens essencialmente midiáticos localiza-se no fait divers, contemporâneo e por vezes fonte de inspiração do folhetim. Ali são encontradas personagenstipo como o político ridicularizado, a mulher assassinada, a criança vitimizada, o policial, o vilão passional.

Mas, o que centraliza o debate neste trabalho é buscar na tipologia das personagens aquelas que se mostrem como possíveis fontes de inspiração na construção das personagenstipo dos espetáculos de realidade. Nesse sentido, toma-se como combustível da síndrome do protagonista, além das personagens do folhetim e do fait divers, os tipos quase sempre recorrentes de produções como:

1) a fotonovela, protagonizada por uma mocinha enfrentando percalços (oferecidos pelo vilão ou vilã) para alcançar sua finalidade, isto é, casar com o mocinho;

2) a radionovela, primeiro produto midiático direcionado ao público feminino (por iniciativa de empresas de produtos de limpeza e higiene), que deu um passo importante para um formato mais "profissional” da indústria cultural, desde os Estados Unidos (com as soap operas), espalhando-se pela América Latina, através do consagrado modelo cubano. Suas personagens-tipo apenas atualizavam em áudio a consagrada fórmula do folhetim: heroína/impedimentos amorosos/casamento com o herói no final;

3) a telenovela que quanto às personagens-tipo secciona-se em duas fases: a primeira, que apenas adotou os protagonistas, antagonistas e coadjuvantes das formas anteriores de folhetim (dos rodapés dos jornais às foto e radionovelas); e a segunda fase, quando novos tipos são esboçados, especialmente a heroína que se adapta às novas figurações da mulher, transformando-se na mocinha moderna e suas variantes (até a prostituta do bem). 
O fato é que essas personagens midiáticas são analisadas no sentido de sua relação de influência na composição dos tipos que vestem os sujeitos comuns ao adentrarem o ambiente midiático nos espetáculos de realidade. Entretanto, em razão da brevidade que exige o presente trabalho, abordam-se apenas quatro dos tipos que se transportam da ficção para os espetáculos de realidade: o casal de protagonistas e seus coadjuvantes.

É possível enumerar diversos aportes na figura do herói: do gentil, abnegado e discreto Dr. Albertinho Limonta de $O$ direito de nascer até o mocinho que se iguala à mulher na busca do 'grande amor' e na exigência de beleza da segunda fase das telenovelas, tempo de ‘sarados’ atores como Marcelo Novaes ou Marcos Pasquim, desfilando sem camisa para exibir as formas conseguidas 'malhando’ em academias de ginástica. O mocinho sarado é um dos tipos da síndrome do protagonista, que pode ser exemplificado por Marcelo Dourado, o Moicano do Big Brother Brasil 44, lutador de 'vale-tudo', formado em Educação Física e dono de uma academia em Porto Alegre.

No entanto, não há alterações mais contundentes do que aquelas que se fazem notar nos papéis femininos introduzidos pela segunda fase da telenovela. A mocinha moderna, como todas as outras heroínas da herança folhetinesca, é lindíssima (seguindo o ciclo evolutivo do padrão de beleza de cada época: houve misses como Vera Fischer e atualmente as estrelas são as egressas das passarelas, top models como Fernanda Lima), generosa (não tem amigos propriamente, mas 'protegidos'), leal e sincera (a mocinha não mente nem trai), gentil (inclusive com os pobres, ao contrário da vilã).

Mas a tais qualidades, para acompanhar a evolução do papel social da mulher pósfeminismo, ela também deve agregar uma vida profissional de sucesso. Além disso, ela assume e resume a pauta do 'politicamente correto', defendendo as questões ecológicas, um cenário político sem corrupção e, sobretudo, a causa que possibilita maior interação pessoal, a das minorias: a mocinha moderna tem amigos pobres, negros ou homossexuais, ou uma filha deficiente, como a Helena (Regina Duarte) de Páginas da vida (de Manoel Carlos, exibida pela Rede Globo, de julho de 2006 a março de 2007), que adotou Clarinha, portadora da Síndrome de Down.

E acrescenta também a sensualidade, ora traduzindo-se em profundos decotes que tardiamente vem acompanhar o “renascimento mamário” que Morin (1989 [1984], p. 17)

\footnotetext{
${ }^{4}$ Marcelo Dourado, no BBB de 2004 estava alinhado à "turma dos ricos”, isto é, entre os jovens de classe média como o lutador Zulu, o empresário paranaense Buba, o publicitário mineiro Eduardo e Juliana. todos com formação universitária, Ao perder a nona disputa em que o público escolheu quem permaneceria no jogo, que Dourado perdeu, ele declarou: "Vou sair deste hospício". No entanto, em 2010, participando novamente (e vencendo) Dourado assumiu outro tipo. Dizia-se pobre e morador de uma favela no Rio de Janeiro.
} 
observou como padrão estético das estrelas de Hollywood e no seu comportamento 'ousado' em relação aos homens. Embora as iniciativas de conquista ainda estejam relegadas às coadjuvantes (a amiga despachada da mocinha, por exemplo) ou à vilã (tal qual a mulher fatal do folhetim), a atitude da mocinha moderna no que diz respeito a seus relacionamentos amorosos está muito distante daquela encontrada nas donzelas folhetinescas: em primeiro lugar, ela não é mais donzela, sua vida sexual é exibida em várias cenas 'de alcova' 5 , pois ela pode trocar (e normalmente troca) de parceiro no desenrolar da telenovela. Mas, da mesma forma como as estrelas de cinema, na Hollywood brasileira, as mocinhas das telenovelas sincretizam as conquistas de liberdade sexual do feminismo com os valores regressivos do folhetim, pois o casamento ainda é o fim.

Entretanto, a telenovela brasileira também agrega um segundo tipo erotizado de mulher: a prostituta do bem. Inicialmente, a personagem lembra a dona do saloon dos filmes de cow boy americanos: a mulher sábia, experiente e generosa, que distribui 'lições de vida', apoia o herói, mas não casa com ele. Na transposição brasileira, a televisão adaptou este tipo para o nordeste retratado nos romances de Jorge Amado, por exemplo. São as donas de 'castelos', como a protagonista de Tieta do Agreste (atuação de Betty Faria, na Rede Globo, em 1989), ou como a coadjuvante Margot, de Terras do sem fim (interpretada por Maria Cláudia, na Rede Globo, em 1982).

Mas não há precedentes para a prostituta do bem de Laços de família (Rede Globo, 2000), vivida pela atriz Giovanna Antonelli, chamada Capitu (como a protagonista de Dom Casmurro, de Machado de Assis, a personagem feminina mais famosa da literatura brasileira). Longe do padrão deste tipo de personagem, ela não é a alegre e caricata quenga das telenovelas de época, ao contrário, insere-se entre as outras mocinhas de Laços de família: sofredora e corajosa, não tem uma 'vida fácil', é arrimo de família e a prostituição no seu caso é apresentada quase como um trabalho como qualquer outro, apenas mais rentável e sujeito a alguns perigos.

Já nos espetáculos de realidade da televisão, um exemplo da mocinha moderna é Juliana, do Big Brother Brasil 4, par romântico de Marcelo Dourado, que manteve uma atuação digna do tipo: politicamente correta, não discriminava os 'pobres' do programa, que recorriam a ela para perguntas que envolviam maior escolaridade. Essa versão do reality show, aliás, foi conhecida como o "BBB da luta de classes”, como comentou a escritora

\footnotetext{
${ }^{5}$ De acordo com Rivera (1968), os dramas de alcova, explorando os conflitos passionais em enredos frágeis que, ao omitir aspectos mais crus da existência humana, difundiam a visão de mundo "adocicada” hoje associada ao folhetim de um modo geral.
}

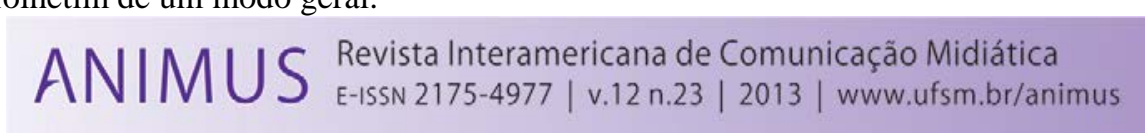


Martha Medeiros para a revista Época ${ }^{6}$ : "Estava na cara que este Big Brother Brasil não seria igual aos que passaram. A entrada de dois participantes por sorteio colocou dentro da casa gente comum como a babá Cida e o office-boy Tiago. E acendeu o sentimento de classe dos jogadores”. A politicamente correta mocinha moderna é transposta para os reality shows de televisão como um tipo inspirado na 'modelo e atriz', e depois de deixar o cenário de confinamento do programa, normalmente passa a integrar a galeria de brasileiras que posam nuas para revistas e sítios dirigidos ao público masculino.

Finalmente, na melhor tradição da commedia dell'arte, os zanni que protagonizavam a ação cômica dessas peças estariam muito bem representados na figura da babá que venceu o Big Brother Brasil 4. Trata-se da mocinha pobre alçada à condição de milionária pelos desígnios democratizantes da audiência que vota pela saída ou permanência dos participantes: apiedando-se quando Cida declara que nunca havia ido ao dentista, mas reservando-se o direito de divertir-se com os erros gramaticais cometidos pela moça ou quando ela, embriagada, tentou uma investida romântica na direção do mecânico Tiago. Ele, apelidado o Dotadão, quando entrando na 'casa' por sorteio recebeu de presente uma festa apenas com a presença das mulheres ('sisters'), formaria com Cida o casal de zanni da estratificação da versão 'luta de classes’ do espetáculo de realidade.

Porém, personagem cômica mais marcante ainda foi Solange, no mesmo Big Brother Brasil de 2004, cantando 'em inglês' a transcrição fonética do que a moça entendia do título da canção We are the world, composta por Michael Jackson e Lionel Richie e cantada por 45 artistas no concerto de rock Live Aid, de 1985. Ironicamente, enquanto a canção teve como objetivo arrecadar fundos em prol dos famintos da Etiópia, a moça pobre e ignorante brasileira é motivo de riso. Acessar o buscador Google com a expressão ‘Iarnuou’ e o nome Solange responde com “aproximadamente 1.030 resultados”. Muitos deles apresentam a maneira como Solange cantou e a letra correta da canção em inglês.

Da Matta (1987, p. 87-88), sob o título "Você sabe com quem está falando?”7 refere-se a um "ritual de reconhecimento” que ajuda “a hierarquizar as pessoas implicadas” em situações de conflito ou disputa, para observar que se o papel de “cidadão” brasileiro "faz parte do ideário da ética pública e dos comícios e programas dos partidos políticos, afirmando que todos são iguais

\footnotetext{
6 “Luta de classes na tevê”, revista Época, ed. 300, 11.02.2004, disponível em: http://revistaepoca.globo.com/Revista/Epoca/0,,EDR62730-6011,00.html. Acesso em 12.03.2006.

${ }^{7}$ A sociologia de Da Matta desenvolve-se a partir do estudo do cotidiano brasileiro, focalizando seus rituais e modelos de ação, como se lê em Carnavais, malandros e heróis: para uma sociologia do dilema brasileiro (Rio de Janeiro: Zahar, 1980). A obra citada aqui analisa mais detidamente a dimensão espacial da dualidade dialética constitutiva de sua sociologia: (casa X rua; indivíduo X pessoa; mercado e individualismo norte-americanos $\mathrm{X}$ sociedade relacional brasileira).
} 
perante a lei, não é assim que a cidadania como um papel social é vivida no cotidiano da sociedade”.

O "ritual de reconhecimento", no caso dos comentários sobre a mocinha pobre parece perpassar os mais de mil sítios da internet estabelecendo a hierarquia entre 'nós, que conhecemos o idioma inglês, porque temos dinheiro para pagar pela formação’ e ‘eles, cuja ignorância é motivo de riso'. Dito de outra maneira, trata-se de uma estrutura de sentimento localizada no espaço de tensão entre o que é vivido por um estrato social - que ambiciona estar entre aqueles que se movem dentro de padrões desejáveis à visibilidade midiática (daí a participação em espetáculos de realidade) - e aqueles que estão ou pensam estar dentre os protagonistas de uma nova maneira de movimentar-se nos 'não-lugares' de uma cultura mundializada, o que os livraria da incômoda identificação com uma cidadania de terceiro mundo.

No entanto, esse sentimento de fazer parte do grupo dos 'cidadãos do mundo', que se articula em inglês, domina a tecnologia que constrói sites e blogs, e tudo o mais que possa ser incluído dentre as convenções de pertencimento ao universo dos ‘superiores’ não está situado no plano cognitivo - porque se estivesse, agregaria também as ideias 'politicamente corretas' daqueles que cantam "nós somos o mundo" e por isso “é hora de atender a um certo apelo” que vem dos famintos e dos pobres. Trata-se de um conhecimento subjetivo da experiência cosmopolita: uma estrutura de sentimento que diz à mocinha pobre que ela não sabe o que está falando, portanto não é uma igual, é uma personagem cômica.

As mesmas atuações 'pitorescas' também são reservadas ao mocinho pobre: construir tipos como o cowboy Rodrigo, do Big Brother Brasil 2, treinador de cavalos e candidato a cantor sertanejo, alçado ao espetáculo de realidade apenas porque “a Globo queria um participante com cara de vaqueiro e que andasse de chapéu”, afirmou a revista Veja de 31.07.2002. Ou, ainda, o infantilizado personagem de desenho de televisão, vencedor da primeira edição do mesmo programa, Bambam, cometendo "toda classe de atropelos gramaticais e léxicos”, como pode reparar o uruguaio Andacht (2003, p. 85).

De certa forma, ao desqualificar estas personagens como 'ignorantes' ou 'pitorescas', trilha-se o caminho regressivo de ver a cultura como um processo de ilustração (ou do que o grupo do “você sabe com quem está falando” julga ser 'instruído', como falar inglês corretamente, por exemplo), que aprofunda os padrões de desigualdade. De outro lado, o “olho mágico” das emissoras de televisão, ao produzir os tipos que alimentam na verdade seu próprio protagonismo no cenário midiático, aponta para o que observou Martín-Barbero (1997 
[1987], p. 39) sobre as "leviandades de uma comunicação aliviada, devido à tecnologia, do peso dos conflitos e da obscuridade dos atores sociais, num processo no qual se liberam as diferenças”, entretanto, sem promover igualdade.

\section{CONSIDERAÇÕES}

\subsection{Para um desenlace}

O que se buscou aqui, enfim, foi rastrear certo padrão de comportamento/atuação que se percebia nos sujeitos comuns, ao observá-los em cena, na mídia. Certamente haverá apresentações de egressos do segmento da recepção midiática em produções — e papéis — que aqui não foram contemplados, bem como deve haver performances não enquadráveis sob qualquer tipologia.

Assim, antes de declarar definitivas as conclusões deste trabalho, cabe por ora, como Miranda, personagem da peça A Tempestade, admirar-se com os espetáculos que a realidade apresenta. Em 1623, Shakespeare criou personagens bizarras (talvez folhetinescas), como Próspero, o duque que é destituído do poder pelo irmão, jogado ao mar e, em uma ilha paradisíaca da América, entre ogros e seres fantásticos, se transforma em habilidoso mago. Sua filha Miranda cresce nesse lugar e, desconhecendo-se inglesa civilizada, ao ver pela primeira vez os homens do Velho Mundo, que atracavam na ilha após um naufrágio, exclamaria: “Oh! Maravilha! Quantas criaturas belas estão aqui! Como é bela a humanidade! Oh, admirável mundo novo em que vivem tais pessoas!” 


\section{REFERÊNCIAS}

ANDACHT, Fernando. El reality show: uma perspectiva analítica de la televisión. Buenos Aires: Grupo Editorial Norma, 2003.

ARISTÓTOLES. Arte Poética. São Paulo: Matin Claret, 2006.

BRENNEN, Bonnie. "Sweat not melodrama: reading the structure of feeling in All the President's Men”. In Journalism: Theory, Practice and Criticism 4(1), 2003. p. 113-131. Disponível em http://www.ijpc.org/watergate.pdf. Acesso em 28.10.2005.

CANCLINI, Néstor García. "Estudos sobre cultura: uma alternativa latino-americana aos cultural studies". Entrevistado por ESCOSTEGUY, Ana Carolina; MORAES, Ana Luiza Coiro; GOELLNER, Renê. Revista FAMECOS nº. 30, Porto Alegre, ago./2006, pp. 7-15

DaMATTA, Roberto. A casa e a rua: espaço, cidadania, mulher e morte no Brasil. Rio de Janeiro: Guanabara, 1987.

DEBORD, Guy. A sociedade do espetáculo. Rio de Janeiro: Contraponto, 1997 [1967].

ESCOSTEGUY, Ana Carolina D. Cartografias dos estudos culturais: uma versão latinoamericana. Belo Horizonte: Autêntica, 2001.

LESKY, Albin. A tragédia grega. São Paulo: Perspectiva, 1976.

LIPOVETSKY, Gilles e CHARLES, Sébastien. Os tempos hipermodernos. São Paulo: Barcarolla, 2004.

MARTÍN-BARBERO, Jesús. Dos meios às mediações: comunicação, cultura e hegemonia. Rio de Janeiro: UFRJ, 1997 [1987].

MOISÉS, Massaud. Dicionário de termos literários. São Paulo: Cultrix, 1974.

MORIN, Edgar. As Estrelas: mito e sedução no cinema. Rio de Janeiro: José Olympio, 1989 [1984].

PROPP, Vladimir. Morfologia do conto maravilhoso. Rio de Janeiro: Forense Universitária, 1984.

RIVERA, Jorge B. El foletin y la novela popular. Buenos Aires: Centro Editor de América Latina, 1968.

WILLIAMS, Raymond. "Culture is ordinary". In GRAY, Ann e McGUIGAN, Jim. Studying culture: an introductory reader. London/New York: Arnold, 1993 [1958]. p. 5-14.

WILLIAMS, Raymond. Marxismo e Literatura. Rio de Janeiro: Zahar, 1979 [1977]. 
Original recebido em: 20/04/2013

Aceito para publicação em: 20/07/2013

Ana Luiza Coiro-Moraes

Doutora em Comunicação Social pela Pontifícia Universidade Católica do Rio Grande do

Sul (PUCRS). Professora Visitante da Universidade Federal de Santa Maria (UFSM)

Programa de Pós-Graduação em Comunicação. 